\title{
CONTRIBUIÇÃO À GEOLOGIA DOS ARREDORES DE REGISTRO, SP
}

\author{
Geólogo PAULO CESAR PRESSINOTTI e \\ Geólogo MARCIA MARIA NOGUEIRA PRESSINOTTI
}

\begin{abstract}
RESUMO
Em linhas gerais, este trabalho versa sobre a geologia, tectônica e ambiente de sedimentação de formações quaternárias, na região do vale do rio Ribeira, parte Sudeste do Estado de São Paulo, resultante de um mapeamento geológico elaborado na escala de 1:50.000 e de estudos sedimentológicos.

Uma síntese das seguintes unidades estratigráficas são apresentadas:

a) migmatitos, xistos e granitos do Pré-cambriano médio;

b) sedimentos inconsolidados da Formação Pariquera-Açu - Pleistoceno;

c) areias marinhas, argilas e turfas do holoceno.

Evidências de falhas gravitacionais, ocorridas ao longo de direções estruturais mais antigas, durante o neocenozóico, são expostas, formando a planície costeira de Cananéia-Iguape.
\end{abstract}

\begin{abstract}
This paper deals about an outline of the geology, tectonics and quaternary depositional environment close to rio Ribeira valley, in the southeast part of São Paulo State, like as a result of geological mapping carried out in scale 1:50.000 and sedimentological studies.

A synthesis of the following units are presented:

a) migmatites, schistes and granite of the middle Pre-cambrian;

b) inconsolidated sediments of the Pleistocene Pariquera-Açu Formation;

c) Holocene marine sands, peats and clay.

Evidences of gravitational faults, occurred in neo-cenozoic, along old directional structures, forming the coastal plain of Cananéia-Iguape are showed.
\end{abstract}

\section{INTRODUÇÃO}

A idealização desta pesquisa, teve início quando em trabalho de prospecção mineral, na várzea do rio Ribeira de Iguape, nas proximidades da cidade de Registro, SP, foi constatada uma extensa área de afloramentos de argilas cinzas de boa plasticidade e uma grande turfeira ao norte da planície costeira de Cananéia-Iguape.

Nessa ocasião, enquanto eram feitos furos de trado, para uma avaliação preliminar do comportamento da camada de argila, visando sua utilização na indústria de cerâmica, executou-se o mapeamento geológico dessa área, tomando-se como limite as rochas do complexo migmatítico, cobertas em parte pela Formação Pariquera-Açu, que formam a área limítrofe a NNW da Planície costeira de Cananéia-Iguape.

O mapa geológico tem por finalidade servir de base para futuras prospecções geológicas e fornecer subsídios para a compreensão da gênese da planície costeira de Cananéia-Iguape, visto que existe um forte controle estrutural em seu limite Norte.

Os resultados conduziram à hipótese da existência de uma reativação tectônica no Cenozóico superior, que aliados a outros dados colhidos sobre o Quaternário, torna oportuno a divulgação desses fatos. 


\section{METODOLOGIA DE TRABALHO}

O trabalho apresentado é resultado de atividade de campo e laboratório, cujo desenvolvimento se sucedeu conforme a sequiência apresentada abaixo:

1. Pesquisa bibliográfica da área.

2. Foto-interpretação em fotografias aéreas na escala, aproximada, de 1:25.000.

3. Levantamento da área, percorrendo-se estradas, caminhos, trilhas e alguns vales de rios, com amostragem de sedimentos e rochas.

4. Furos de trado para uma averiguação da espessura e distribuição da argila e turfa na várzea do rio $\mathrm{Ri}$ beira.

5. Análise granulométrica dos sedimentos da Formação Pariquera-Açu e areias marinhas, no intuito de um estudo sedimentológico.

6. Análise em secção delgada de rochas para uma caracterização petrográfica e petrológica do embasamento.

7. A elaboração de um mapa geológico na escala de 1:50.000, utilizando-se como base topográfica os mapas do IBGE, que recobrem a área, sendo que em muitos lugares, a densidade do controle de campo, permitiria um detalhamento de $1: 25.000$.

8. Análise de difratometria de raio $X$ em amostras de argila do holoceno, para a caracterização mineralógica das argilas.

\section{ASPECTOS GEOMORFOLÓGICOS}

A área estudada situa-se no Baixo vale do rio Ribeira de Iguape, limitada ao Norte pelas rochas do Complexo Brasileiro que barram a planície costeira Cananéia-Iguape, segundo um alinhamento estrutural E-W.

O principal rio da região é o Ribeira de Iguape que acompanha a serra de Paranapiacaba, com uma direção geral NE-SW, e na cidade de Sete Barras, ao receber as águas do rio Juquiá, toma uma direção geral N-S, rompendo próximo a cidade de Registro um alinhamento estrutural E-W. Ao romper este alinhamento o rio Ribeira passa a alojar-se na planície costeira $\mathrm{Ca}$ nanéia-Iguape que, localmente, tem uma largura de $20 \mathrm{~km}$, percorrendo $40 \mathrm{~km}$ por essa planície até chegar a sua fóz.

A delimitação da planície costeira ao Norte é formada, predominantemente, por rochas do cristalino que se elevam, formando encostas abruptas seguindo direções E-W ou NE-SW. Embora as encostas já tenham sofrido a ação do intemperismo e erosão da drenagem, guarda ainda, um caráter geomorfologicamente contrário, ou seja, com o menor caimento do lado oposto à planície costeira. Alojado no interior deste caimento encontram-se os sedimentos da Formação Pariquera-Açu, formando relevo de formas tubulares com pequenas elevações.

A área costeira Cananéia-Iguape apresenta-se plana, com cota média de $8 \mathrm{~m}$. $\mathrm{O}$ rio Ribeira é tipicamente meandrante, sendo nítido nas fotografias aéreas os meandros abandonados, inclusive paleocanais, que rumam em direção ao rio $\mathrm{Pe}$ ropava, mostrando ser este $\mathrm{o}$ antigo canal do rio Ribeira.

\section{ESTRATIGRAFIA}

A área mapeada é constituída pelas seguintes unidades estratigráficas:

1. Complexo Brasileiro representado por migmatitos diversos, gnaisse de injeção, quartzo, sericita xistos e granito.

2. Formação Pariquera-Açu representado por um conglomerado basal e arenitos argilosos inconsolidados.

3. Sedimentos arenosos marinhos.

4. Aluviões argilosos e turfas associadas ao rio Ribeira e Jacupiranga.

\section{PRECAMBRIANO MÉDIO}

Complexo Brasileiro - Constituído por migmatitos, quartzo, sericita xistos e granitos. Dentre os migmatitos reconhecem-se os de estruturas estromatítica que foram denominadas de gnaisse de injeção no mapa geológico (vide mapa n. ${ }^{\circ}$ 2). Macroscopicamente trata-se de uma rocha formada pela alternância de bandas leucocráticas e mesocráticas de espessura centimétrica, que correspondem ao neossoma e paleossoma, 
respectivamente. Mineralogicamente reconhecem-se no neossoma, o quartzo e o feldspato potássico com o aparecimento de porfiroblastos deste mineral deformado e, a textura é grosseira; no paleossoma reconhecem-se a biotita e anfibólio e a textura é média.

A rocha não apresenta xistosidade, porém o bandeamento formado pelos leitos claros e escuros tem orientação regional que varia de ENE-WSW a E-W com mergulho acentuado para Sul.

Migmatitos com outras estruturas ocorrem na área, porém o estado de alteração da rocha não permitiu uma separação petrográfica da mesma e, por isso, foram denominadas genericamente de migmatitos indiferenciados.

\section{DESCRIÇÃO MICROSCÓPICA}

- Amostra PR-131 - migmatito corismito (vide planta de localização de afloramentos, mapa $n .^{\circ} 1$ ).

\section{A) Composição Mineralógica:}

Paleossoma:

a) Quartzo: Apresenta-se, geralmente, com tamanho em torno de $0,1 \mathrm{~mm}$ e com entrelaçamento suturado, característico de rocha metamórfica. Extinção ondulante.

b) Oligoclásio: Geminado polissinteticamente, tamanho variado de $0,05 \mathrm{~mm}$ a $0,3 \mathrm{~mm}$, xenoblástico.

c) Hornblenda: Xenoblástica, tamanho usual em volta de $0,5 \mathrm{~mm}$, pleocróica, com inclusões de quartzo e apatita xenomórficos.

d) Biotita: Xenoblástica, tamanho usual de $0,4 \mathrm{~mm}$, pleocróica, com folhas inbricadas mostrando sua origem metablástica, formando, geralmente, coroas irregulares em torno de cristais do neossoma. A biotita é um tipomórfico de grande divergência, pois vem desde o facies de xisto verde até o de anfibólio. A presença de hornblenda confere ao paleossoma facies do anfibolito e a rocha original seria um biotita hornblenda xisto.

e) Apatita: Xenoblástica.

Neossoma.

a) Ortoclásio Micropertita: Ocorre xenoblástico, com tamanhos entre 0,2 e $0,4 \mathrm{~mm}$, dispondo-se a micropertita em forma de cordel. b) Microlina: Constitui o mineral mais freqüente do neossoma logo após o quartzo, xenoblástica e tamanho de $0,4 \mathrm{~mm}$.

c) Quartzo: Xenoblástico, com tamanho em volta de $0,7 \mathrm{~mm}$ e com extinção ondulante.

B) Classificação: Trata-se de um corismito, um migmatito de escala macropolisquemática, em que o paleossoma e o neossoma se alternam irregularmente em faixas de espessura variáveis (em centímetros).

\section{Estromatítico.}

A composição mineralógica é a mesma, trata-se do mesmo migmatito, porém, classificável como Estromatítico.

Os quartzo-sericita xistos, são rochas de textura grosseira, leucocráticas, ocorrem preferencialmente limitando a planície costeira ao Norte, formando uma crista alongada de direção E-W, que coincide com a direção geral da xistosidade da rocha, com mergulho para Sul. Macroscopicamente, podem ser conhecidos sericita e argila que envolve os grãos de quartzo; freqüentemente apresentam leitos de quartzo alongados, sub-paralelos e leitos contorcidos de um material branco decomposto. Esta rocha constitui as cristas mais elevadas da área.

- Amostra PR-128 - Breccia de sericita xisto.

\section{A) Composição Mineralógica:}

a) Quartzo: Ocorre xenomórfico, com forma alongada ou ovalada, com cataclasse e extinção ondulante. Tamanho muito variado, desde cristais milimétricos até um centímetro. Excepcionalmente, há cristais centimétricos muito cataclasados. As fraturas dos cristais maiores são preenchidas por sericita, demonstrando que a sericitização é um processo epigenético, posterior à cataclase.

b) Sericita: Muito abundante e disposta em leitos irregulares envolvendo o quartzo. Restos de muscovita alterada em sericita, são encontrados em feixes, mostrando que, ainda, não perdem a forma laminar (lepidoblástica). A sericita resultou de um processo hidrotermal deutérico.

B) Classificação: A rocha era originalmente um muscovita xisto ou um muscovita pegmatito que sofreu metamorfismo dinâ- 
mico, evidenciado pela cataclase do quartzo. As evidências petrográficas, são a favor de uma brecciação por falha e, posterior, sericitização por ação hidrotermal a qual é, também, responsável pela cristalização de cristais microscópicos de quartzo, ocasionando duas gerações de quartzo. Nos feixes de muscovita, já alterados em sericita, há feixes de exsolução de magnetita o que indicaria, também, alguma biotita original. A rocha seria uma Breccia de Sericita-xisto.

Em destaque topográfico a SW da área ocorre um "stock" granítico. E um granito leucocrático de cor cinza esbranquiçado ou rósea claro; textura granular, por vezes xistosa - gnaíssica fraca. Macroscopicamente, reconhecem-se o quartzo, o feldspato e a biotita. Microscopicamente, apresentam as seguintes características:

\section{- Amostra PR-072 - Microclina - Granito Cataclástico.}

A) Textura: Hipidiomórfica granular, cristais de quartzo maiores e alongados, cataclase nos cristais de quartzo. Os demais minerais de aspecto granular.

\section{B) Composição Mineralógica:}

a) Quartzo: apresenta-se ora alongado, ora granular, porém com entrelaçamento de sutura, extinção ondulante, cataclasados, tamanho mais comum entre 0,05 e $3,0 \mathrm{~mm}$.

b) Microclina: hidiomórfica a granular; inclusões ou restos de plagioclásio e quartzo; xenomórfica; tamanho mais comum entre 0,5 e $3,0 \mathrm{~mm}$; micropertita em forma de cordel.

c) Oligoclásio: quase todos os indivíduos mostram saussuritização indicando ação por fluídos metassomáticos, porém não aditivos (hidrotermal). Inclusões de quartzo; tamanho variável, no mínimo $3 \mathrm{~mm}$; xenomórfico.

d) Biotita: rara, xenomórfica; bordas sericitizadas; sem orientação.

e) Acessórios: Apatita, Magnetita xenomórfica.

C) Classificação: Microclina - granito cataclástico.

- Amostra PR-069 - Microclina Granito Cataclástico.

A) Textura: A rocha é cristalina com textura suturada (HEINRICH, E. MICROSCOPIC PETROGRAPHY, pg. 176).
Esta textura é característica das rochas metamórficas, onde o entrelaçamento é muito irregular, como o das peças de um quebra cabeça.

\section{B) Composição Mineralógica:}

a) Quartzo: Xenoblástico; tamanho entre 0,2 e $1,30 \mathrm{~mm}$; os cristais exibem cataclase e extinção ondulante; inclusões de biotita e apatita.

b) Microclina: xenoblástica; tamanho entre 0,12 e $1,45 \mathrm{~mm}$; inclusões de quartzo, biotita e albita; apresenta cataclase.

c) Plagioclásio = Oligoclásio: xenoblástico, tamanho entre 0,09 e $0,55 \mathrm{~mm}$; clinozoisita por decomposição do plagioclásio; inclusões de quartzo.

d) Biotita: xenoblástica; tamanho entre 0,09 e $0,50 \mathrm{~mm}$; apresenta cataclase forte; alinhamento fraco.

e) Acessórios: Apatita, Zircão idiomórfico; e Magnetita xenomórfica.

Evidências texturais em seção delgada indicam que a rocha original era de textura granular a hipidiomórfica de natureza ígnea. A microclina teria crescido à custa do plagioclásio e da biotita, sendo um produto de metablastese. A rocha ígnea original era um granito sofrendo posterior metamorfismo dinamotermal, porque a biotita foi quase que, totalmente, reabsorvida para formar a microclina. A microclina pertence a um segundo estágio, ocorrendo a custa do oligoclásio e da biotita.

A análise petrográfica indica que as rochas metamórficas foram submetidas a mais de um evento metamórfico, sendo, portanto, policíclicas. A rocha granítica seria do tipo tardicinemático que foi submetido a um metamorfismo dinamotermal durante a orogenia BAIKALIANA OU ASSINTICA. A natureza metamórfica policíclica levou-nos a situar estas rochas no Pré-Cambriano médio.

\section{PLEISTOCENO - FORMAÇÃO PARIQUERA-AÇU}

A Formação Pariquera-Açu já foi objeto de estudo por parte de diversos autores como: SILVEIRA (1950); RICH (1953); ALMEIDA (1964); BIGARELLA \& MOUSINHO (1965); FRANZINELLI (1970). 


\section{DESCRIÇÃO DOS SEDIMENTOS}

A Formação Pariquera-Açu assenta discordantemente sobre as rochas do complexo migmatítico. $\mathrm{Na}$ base da Formação ocorre um conglomerado arcoziano com seixos e calhaus predominantemente de quartzitos, de diversos tipos: grosseiros, finos, xistosos, fibrosos predominantemente de cores claras. O grau de arredondamento varia de afloramento, podendo encontrar-se arredondados até angulosos, porém de maneira homogênea; em cotas mais inferiores os seixos tendem a ser mais arredondados. Seixos e calhaus de quartzo também ocorrem, porém, de forma sempre subordinada; qualitativamente pode-se dizer que a razão do número de seixos de quartzitos para o número de seixos de quartzo, tende a decrescer conforme diminui o tamanho dos seixos no afloramento.

A estrutura observada foi a macro-estratificação cruzada de baixo ângulo, formado pela alternância de conglomerado e arenito conglomerático. Estruturas do tipo escavação e preenchimento "cut and fill", também, foram observadas relacionadas ao conglomerado basal. No topo do conglomerado, não raro, tem-se uma maior concentração de seixos e uma ausência relativa de matriz, como se a mesma houvesse sido removida após a sedimentação. A forma dos seixos varia de lamelares a discóides, e em forma de bastão quando imposto pela textura da rocha.

A cor do conglomerado é cinza clara, quando não sujeitos a ação de oxidação e as cores avermelhadas de hidróxidos de ferro predominam. A espessura chega a ser superior a $5 \mathrm{~m}$, espessuras de $1,5 \mathrm{~m}$ a $2,0 \mathrm{~m}$, são comuns. Se o conglomerado basal não ocorrer tem-se, geralmente, um arenito conglomerático ou linhas de seixos no contato com o embasamento.

Sobrepõe-se ao conglomerado um arenito argiloso de cor marron amarelada com grânulos e seixos de quartzo esparsos na matriz. A camada é inconsolidada, bastante homogênea, maciça com ampla extensão lateral, de aspecto semelhante aos sedimentos da Formação Rio Claro e/ou Formação Piraçununga no NE do Estado de São Paulo.

Um arenito quartzoso médio de cor cinza claro de matriz argilosa, semiconsolidado possui ocorrência em áreas res- tritas, como a que ocorre próximo do Campo de Pouso de Registro. Sob estes arenitos o conglomerado basal da Formação possui uma cor cinza clara.

Sedimentos argilosos de cores mescladas referidas por BIGARELLA \& MOUSINHO (1965) como sedimentos de "bajada" ocorrem sem expressão lateral; areia grossa e grânulos encontram-se dispersos na matriz, possuem aspectos maciços.

\section{NIVEIS DE TERRACEAMENTO}

De trabalhos prévios, já é conhecido que a deposição da Formação Fariquera-Açu está controlada por níveis de terraceamento. De acordo com BIGARELLA (1965) "os sedimentos da Formação Pariquera-Açu constituem depósitos correlativos dos fenômenos que culminaram com o aplainamento do Pediplano Pdl. Embutidos dentro desta superfície encontram-se mais dois sistemas de alvéolos, elaborados durante a Pedimentação P2 e PI". Desta forma, a Formação resulta de três níveis de terraceamento que o referido autor, ainda, correlaciona com eventos glaciais no hemisfério Norte. Em 1951 FREITAS já mencionava terraços fluviais, do litoral do Estado de São Paulo, em níveis de 50 a $60 \mathrm{~m}$; de 25 a $30 \mathrm{~m}$ sobre o rio e barrancas de 2 a $5 \mathrm{~m}$; FRANZINELLI (1970) menciona terraços fluviais em níveis de 50 a $60 \mathrm{~m} ; 25$ a $30 \mathrm{~m}$ e 7 a $8 \mathrm{~m}$.

$\mathrm{Na}$ área mapeada, os sedimentos da Formação Pariquera-Açu se correlacionam ao nível de terraceamento de 25 a $30 \mathrm{~m}$, porém, não como regra, pois o conglomerado basal da formação aflora em níveis de até $7 \mathrm{~m}$ sobre o nível de base do rio. Não foi possível caracterizar a pedimentação sugerida por BIGARELLA (op. cit.) ao longo de toda área, porém, pode-se notar a existência de diferentes terraços para a deposição do conglomerado basal da Formação.

\section{BACIA E AMBIENTE DE SEDIMENTAÇÃO}

A bacia de sedimentação da Formação Pariquera-Açu deve ter tido seu preenchimento quando o rio Ribeira já fluia para o Atlântico; esta bacia seria circumpiemôntica em que a face Sudeste, voltada para a costa, seria limitada por barreiras 
de direções E-W e NE-SW, que serviram para o represamento dos sedimentos. Tais barreiras seriam o limite NW de outra bacia de sedimentação que, atualmente, se configura como a planície costeira de Cananéia-Iguape.

Nesta área, flutuações climáticas entre os climas semi-árido e úmido, teriam formado os terraços fluviais. Em épocas semi-áridas ocorreria um aplainamento intermontano; quando ocorresse uma flutuação climática, em direção ao úmido, haveria uma dissecação ao longo das drenagens, com o rebaixamento do nível de base local. Em um estágio posterior quando nova mudança climática se efetuasse para condições semi-áridas, teríamos um aplainamento lateral formando, então, os terraceamentos que manteriam estreito correlacionamento ao longo da drenagem, que é utilizado, então, como nível de base. Esse aspecto é mostrado ao longo do rio $\mathrm{Ri}$ beira, rio Jacupiranga e rio Carapiranga, próximo a Registro, onde temos bem definidos os terraços preenchidos por sedimentos argilosos e turfas que caracterizam o clima úmido atual. Esse terraceamento teria ocorrido em época pretérita, em fins do Pleistoceno.

O conglomerado basal da formação teria se depositado em épocas torrenciais, após processos morfomecânicos em ambiente semi-árido. Os sedimentos, que recobrem o conglomerado, teriam se depositado em épocas úmidas com um tipo de transporte de massa em meio viscoso, como foi evidenciado pelos estudos sedimentológicos.

\section{HOLOCENO}

\section{a) Areias Marinhas.}

Areias marinhas aflorantes ocorrem ao Sul do "stock" granítico. São areias quartzosas, finas, micáceas de matriz argilosa com destaque topográfico sutil. Sambaquis estão situados sobre estas areias, cuja datação pelo método do $\mathrm{C}^{12}$ em conchas deste sambaquis efetuadas por SUGUIO \& MARTIM (1978) acusou idade de $4.210 \pm$ 120 B.P. Em superfície este foi o único testemunho de praia suspenso encontrado, sem estar coberto por argilas aluvionares do Ribeira. Há a possibilidade de ocorrer outros testemunhos, mas que devido a cobertura vegetal e terrenos alagadiços não foram encontrados.
Alguns furos de trado, revelaram que à profundidade de cerca de $2,0 \mathrm{~m}$ na várzea do rio Ribeira, ocorrem areias finas, pouco micáceas. Essas areias seriam, também, de origem marinha, como foi evidenciado pelos estudos sedimentológicos.

\section{b) Argilas e Turfas}

Recobrindo as areias marinhas encontram-se os depósitos aluvionares do rio Ribeira, que são constituídos por argila de cor cinza claro ou cinza esverdeado com restos de madeira, folhas e ramos. Lentes de argilas turfosas ou turfa podem ocorrer intercaladas. A argila é micácea, pouco arenosa, e à medida que a camada se aproxima da margem do rio o teor da fração areia aumenta.

Para caracterização mineralógica da argila, foram feitas pelo IPT (Certificado n. ${ }^{\circ}$ 574.933), análises de difração de raio $\mathrm{X}$ e perda ao fogo a $550^{\circ}$ de 04 amostras, que revelaram as seguintes características:

- Amostra TR-10

óxido de silício: $\mathrm{SiO}_{2}$ (quartzo alfa). Silicato de alumínio hidratado: $\mathrm{Al}_{2}$ $\mathrm{Si}_{2} \mathrm{O}_{5}(\mathrm{OH})$ caulinita.

Minerais dos grupos das micas e feldspatos e, possivelmente, óxido de titânio: $\mathrm{TiO}_{2}$ (rutilo).

Perda ao fogo $10.9 \%$.

- Amostra Poço 1

Silicato de alumínio hidratado $\mathrm{Al}_{2}$ $\mathrm{Si}_{2} \mathrm{O}_{5}(\mathrm{OH})_{4}$ (caulinita).

Óxido de silício: $\mathrm{SiO}_{2}$ (quartzo alfa). Minerais dos grupos das micas, montmorilonistas e feldspato e, possivelmente, óxido de titânio $\mathrm{TiO}_{2}$ (rutilo).

Perda ao fogo $9.75 \%$.

- Amostra TR-3

Óxido de silício: $\mathrm{SiO}_{2}$ (quartzo alfa). Silicato de alumínio hidratado: $\mathrm{Al}_{2}$ $\mathrm{Si}_{2} \mathrm{O}_{5}(\mathrm{OH})_{4}$ caulinita e mineral do grupo das micas.

Perda ao fogo $10.7 \%$.

\section{- Amostra TR-4}

óxido de silício: $\mathrm{SiO}_{2}$ (quartzo alfa). Silicato de alumínio hidratado: $\mathrm{Al}_{2}$ $\mathrm{Si}_{2} \mathrm{O}_{5}(\mathrm{OH})_{4}$ caulinita.

Minerais do grupo das micas e feldspato e, possivelmente, óxido de titânio. 
Um depósito de turfa ocorre entre o rio Ribeira e o limite Norte da planície costeira próxima a Registro. Este depósito possui seu maior comprimento na direção $\mathrm{E}-\mathrm{W}$, chegando a atingir ao menos $5 \mathrm{~km}$, pois, na margem direita do rio Ribeira a turfa está sotoposta por camada argilosa entre esse rio e o Carapiranga. A sua maior largura deve alcançar $1,5 \mathrm{~km}$. Tal depósito turfoso deve ter tido sua deposição em uma bacia de sedimentação lacustre quando ocorreram as transgressões marinhas do Quaternário que teriam barrado o rio Ribeira à montante.

\section{ESTUDOS SEDIMENTOLÓGICOS DA FORMAÇÃO PARIQUERA-AÇU E AREIAS MARINHAS}

\section{Representação dos Dados}

Para efeito de um estudo sedimentológico foram analisadas 34 amostras de sedimentos, subdivididas em 03 grupos de amostras, conforme a unidade geológica e litológica a que pertenciam. (Tab. 1)

a) grupo das areias marinhas e areias marinhas retrabalhadas; 13 amostras;

b) grupo da Formação Pariquera-Açu - cinza a branco - (não oxidadas): 06 amostras;

c) grupo da Formação Pariquera-Açu - castanho amarelado (oxidadas): 14 amostras.

Os dados obtidos através das análises granulométricas estão apresentados em tabelas, gráficos e figuras. (Figs. 1 a 6 e Tabs. de 2 a 5)

\section{INTERPRETAÇÕES}

a) Diagrama triangular: (Fig. 1) Observa-se que, somente, 02 dos três grupos estudados possuem posições relativamente bem definidas nesse tipo de gráfico. São os grupos formados pelo sedimento da Formação Pariquera-Açu cinza e branco e castanho amarelado. O terceiro grupo de amostras, de areias marinhas, não possui posição bem definida, sugerindo que as mesmas sofreram retrabalhamento e, portanto, a participação de outros fatores de sedimentação que modificaram as características das areias depositadas em ambiente marinho.
Nesse diagrama, verifica-se que os sedimentos da Formação Pariquera-Açu (cinza a branco) são mais arenosos ( \pm entre $65 \%$ a $85 \%$ de areia) que os da Formação $\mathrm{Pa}$ riquera-Açu (castanho amarelada) ( \pm entre $35 \%$ a $62 \%$ de areia), possuindo ambos uma quantidade de silte inferior a $25 \%$.

b) Gráfico das Curvas Acumulativas: (Fig. n. ${ }^{\circ}$ s 2, 3 e 4) - Estudando-se os gráficos obtidos, de cada grupo, verifica-se que o comportamento dessas curvas nos dois grupos de amostras da Formação Pariquera-Açu são similares, enquanto que o obtido dos sedimentos de areias marinhas, possui um padrão de comportamento totalmente diferente dos dois grupos mencionados.

Note-se no gráfico do grupo das areias marinhas que esses sedimentos possuem um bom selecionamento entre as frações de areia fina a muito fina $(\varnothing 2$ a 4$)$, demonstrado pelo primeiro patamar. Esse comportamento corrobora com uma deposição marinha para esses sedimentos. E importante ressaltar, aqui, que há algumas curvas que fogem ao comportamento citado (1..$^{\circ}$ patamar) sugerindo, portanto, mais uma vez, que houve retrabalhamento em alguns desses sedimentos e, possivelmente, de caráter fluvial.

Os outros dois gráficos (n. ${ }^{\circ}$ s 4 e 5 ) ambos da Formação Pariquera-Açu, mostram curvas de comportamento típico de sedimentos de depósitos fluviais, embora possuam diferenças entre si, quanto a quantidade presente de areia $\mathrm{x}$ argila.

c) Gráfico de Barras do número de Classes (Fig. n. ${ }^{\circ}$ 5) - Baseando-se na escala de Wenthworth, verifica-se que a maioria dos sedimentos da Formação $\mathrm{Pa}$ riquera-Açu possui grande número de classes texturais (entre 12 e 11 classes), chegando-se até a encontrar as de seixos (12. ${ }^{\mathrm{a}}$ classe). $\mathrm{O}$ grande número de classes texturais sugere que esses sedimentos tenham sofrido um curto transporte em grandes massas, portanto, de grande competência.

Os sedimentos marinhos ao contrário possuem em sua maioria um número maior de classes texturais ( \pm 8 classes), sugerindo um agente transportador mais moderado e seletivo.

d) Gráfico de SAHU (1954). (Fig. 6)

O diagrama de SAHU (1964) indica que: as amostras do grupo das areias ma- 
rinhas (subgrupos I e II) evidenciam o ambiente de sua deposição - marinho raso - com energia média; - as amostras da Formação Pariquera-Açu oxidadas foram depositadas em ambiente fluvial, quase de turbidez, sob condições de transporte de alta viscosidade, embora, conforme sua posição geográfica, apresentam variações de energia; - não foi possível definir, como se pretendia, um subambiente para a Formação Pariquera-Açu não oxidada, pode-se, apenas, estimar as variações de energia com o grupo oxidado.

e) Tabelas dos Parâmetros Texturais (Tab. 2 a 5):

Baseado nas tabelas de Distribuição Percentual de Amostras dos Parâmetros Granulométricos de Folk e Ward, e da Distribuição total e Areia, chegou-se às seguintes características granulométricas:

- Areias marinhas e areias marinhas retrabalhadas:

Os seus sedimentos são, em sua maioria, arenosos pobremente selecionados de distribuição bimodal.

O diâmetro médio, da maioria desses sedimentos, está entre silte grosso e silte médio, embora note-se uma forte tendência a frações grosseiras.

Estudando-se, apenas, as frações arenosas desses sedimentos, verifica-se que as características acima alteram-se radicalmente; o diâmetro médio predominante encontra-se na classe de areia fina, sendo muito bem selecionados, com tendências a frações finas e de distribuição quase que, totalmente, unimodal.

Isto sugere que esses sedimentos foram depositados, inicialmente, em ambiente marinho e, posteriormente, sofreram influência de um outro ambiente deposicicnal dominante na região, de caráter fluvial.

\section{- Formação Pariquera-Açu:}

Estudou-se, separadamente, dois tipos de sedimentos encontrados nessa formação: os sedimentos não oxidados (cinza a branco) e cs oxidados (castanho amarelados).

Os sedimentos não oxidados são mais arenosos, enquanto que os oxidados possuem, em sua maioria, maior predominância da fração argila.

O diâmetro médio predominante do material não oxidado, está no intervalo de silte grosso, possuindo uma forte tendência a frações grosseiras, ao passo que o diâmetro no material oxidado está no intervalo de silte fino com tendência a frações argilosas.

Considerando-se, apenas, as frações arenosas de cada grupo de amostras, verifica-se que as características texturais granulometricas se mantém, com exceção do diâmetro médio que passa a predominar, em ambos os grupos, no intervalo de areia média a fina. Essas areias são pobremente selecionadas e de distribuição polimodal.

As características encontradas nos sedimentos oxidados são comuns naqueles depositados em ambiente continental, subaéreo cujo agente transportador é de caráter não seletivo e de grande competência.

Esses sedimentos possuem a assimetria negativa a muito negativa, ou seja, com grandes tendências às frações finas, argilosas (quimicamente estáveis) e considerando que estes sedimentos foram depositados em ambiente de quase turbidez e de alta viscosidade, conclui-se que a área fonte dos sedimentos da Formação Pariquera-Açu esteve exposta a forte intemperismo químico, produzindo um regolito que sofreu transporte tipo em lençol de massa.

O compcrtamento dos sedimentos não oxidados sugere a influência de um subambiente de origem subaquática dentro de um macro ambiente subaéreo.

\section{CONCLUSÕES}

Com base nos dados obtidos, através de trabalhos de campo e laboratório, pode-se conhecer a área dos arredores de Registro, SP, quanto à tectônica, possibilidades econômicas e características dos ambientes deposicionais dos sedimentos que constituem a planície nessa área.

\section{CARACTERISTICAS DOS AMBIENTES DEPOSICIONAIS DAS FORMAÇÕES SEDIMENTARES}

O estudo dos arenitos da Formação Pariquera-Açu, revelou que esses sedimentos foram depositados em ambiente fluvial de quase turbidez, sob condições de transporte de alta viscosidade, em grandes massas.

A área fonte desses sedimentos, que se encontram oxidados, esteve exposta a forte intemperismo químico, contribuindo com 
um transporte tipo em lençcl, depositados em ambiente subaéreo. .Já os sedimentos que se encontram não oxidados, tiveram influência, durante a deposição, de um ambiente subaquático dentro de um macro-ambiente subaéreo.

$\mathrm{O}$ estudo das areias marinhas revelou a influência de um ambiente de caráter fluvial nas areias inicialmente depositadas em ambiente de mar raso.

\section{TECTÔNICA}

Pressupõe-se que a gênese da planície costeira de Cananéia-Iguape, seja de origem tectônica. Conforme pode ser visto no mapa geológico, a planície costeira é fortemente controlada por lineamentos estruturais de direção geral E-W ou NE-SW. Outros fatos que parecem vir a favor da origem tectônica da planície costeira são:

a) alinhamento das cristas e bordas retilíneas que limitam essa planície ao longo das direções estruturais;

b) a planície costeira apresenta-se como um patamar escalonado em relação a superfície de deposição da Formação Pariquera-Açu;

c) coincidência entre xistosidade e direçãc estrutural dos lineamentos;

d) a retenção dos sedimentos da Formação Pariquera-Açu, está controlada pela existência das cristas e bordas retilíneas;

e) a análise petrográfica das rochas, das encostas cristalinas mostraram cataclasamento nos seus minerais.

Esses argumentos levam à suposição de que a formação da planície costeira teve origem por falhamentos de gravidade com abatimento do bloco costeiro. Os falhamentos seriam reativações de outros mais antigos, pois as direções estruturais E-W e NE-SW correspondem respectivamente às direções estruturais das cintas orogênicas mais antigas.

A idade provável das falhas, que limitam a planície costeira é miocênica ou pliocênica, em virtude dos sedimentos da Formação Pariquera-Açu terem se depositado no Pleistoceno.

Confirmada a origem tectônica da planície costeira, torna-se presumível que a superfície de deposição da Formação Pariquera-Açu corresponde a um patamar superior de um sistema de falhamentos de gravidade que forma um modelo estrutural dos blocos escalonados para o litoral sul do Estado de São Paulo.

\section{POSSIBILIDADES ECONÔMICAS}

Depósitos argilosos sedimentares são largamente distribuî́dos na planície costeira com uma maior porcentagem de fração areia próximo ao rio Ribeira. Esses depósitos argilosos são ricos em matéria orgânica e, freqüentemente, apresentam-se impregnados de limonita. Uma única análise tecnológica em amostra de argila cinza de boa plasticidade, feita pelo IPT - Certificado n. ${ }^{\circ} 574.374$ - revelou seu uso possível em cerâmica vermelha. Porém, afloramentos de conglomerado arcoziano caulinizados, não oxidados, foram localizados e estudos mais detalhados podem revelar esse conglomerado como fonte de argila para uso em cerâmica branca.

Outra possibilidade econômica para a região é o aproveitamento de turfas, pois além de turfeira mapeada, ocorrem outras largamente distribuídas na área.

Essas turfeiras que já foram motivo de estudo por parte de KNECHT (relatório inédito), carecem de maiores especificações tecnclógicas, para que se possa definir sua potencialidade como fonte energética. 
Rev. IG, São Paulo, 1(2):5-24, jul./dez. 1980

TABELA 1 - Agrupamento das Amostras

\begin{tabular}{|c|c|c|c|c|}
\hline GRUPO & $\begin{array}{c}\text { AMOSTRA } \\
\text { N. }\end{array}$ & $\underset{\%}{\text { AREIA }}$ & $\underset{\%}{\text { SILTE }}$ & $\begin{array}{c}\text { ARGILA } \\
\%\end{array}$ \\
\hline  & $\begin{array}{l}61 \\
\text { TR-5/0,30-0,40 m } \\
\text { TR-5/0,95-1,05 m } \\
\text { TR-5/1,50-1,60 m } \\
\text { TR-5/1,95-2,05 m } \\
\text { TR-5/2,45-2,55 m } \\
\text { TR-5/2,85-2,95 m } \\
\text { TR-6/1,30 m } \\
\text { TR-6/1,45-1,55 m } \\
\text { TR-7/1,60-2,10 m } \\
\text { TR-7/2,10-2,40 m } \\
\text { TR-8/3,10-3,15 m } \\
\text { TR-8/3,15-3,40 m }\end{array}$ & $\begin{array}{l}53 \\
61 \\
52 \\
64 \\
62 \\
74 \\
58 \\
11 \\
15 \\
21 \\
38 \\
27 \\
53\end{array}$ & $\begin{array}{l}27 \\
18 \\
17 \\
21 \\
10 \\
11 \\
26 \\
23 \\
27 \\
51 \\
43 \\
44 \\
31\end{array}$ & $\begin{array}{l}20 \\
21 \\
31 \\
25 \\
28 \\
15 \\
16 \\
66 \\
58 \\
28 \\
19 \\
29 \\
16\end{array}$ \\
\hline 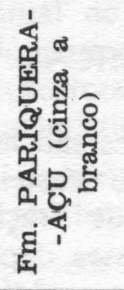 & $\begin{array}{lll} & & 93 \\
149 & \text { A } & \\
150 & \text { A } & 1 \\
150 & \text { A } & 2 \\
150 & \text { A } & 3 \\
150 & \text { A } & 4\end{array}$ & $\begin{array}{l}50 \\
67 \\
62 \\
57 \\
62 \\
65\end{array}$ & $\begin{array}{r} \\
17 \\
9 \\
23 \\
21 \\
16 \\
16\end{array}$ & $\begin{array}{l}33 \\
24 \\
15 \\
22 \\
22 \\
19\end{array}$ \\
\hline 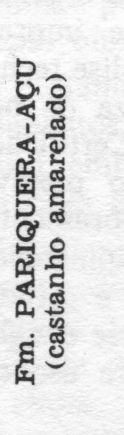 & $\begin{array}{l}26 \text { B } \\
29 \\
31 \\
73 \\
74 \\
77 \\
78 \\
86 \text { B } \\
122 \\
127 \\
137 \\
139 \\
142 \mathrm{C}\end{array}$ & $\begin{array}{l}44 \\
39 \\
48 \\
53 \\
38 \\
50 \\
37 \\
35 \\
41 \\
46 \\
37 \\
30 \\
40 \\
40\end{array}$ & $\begin{array}{r}7 \\
6 \\
8 \\
8 \\
9 \\
10 \\
10 \\
17 \\
18 \\
5 \\
8 \\
6 \\
8 \\
4\end{array}$ & $\begin{array}{l}49 \\
55 \\
44 \\
39 \\
53 \\
40 \\
53 \\
48 \\
41 \\
49 \\
55 \\
64 \\
52 \\
56\end{array}$ \\
\hline
\end{tabular}

TABELA 2 - Parâmetros Texturais - Diâmetro Médio - \% de Amostra DISTRIBUIÇÃO TOTAL

\begin{tabular}{|c|c|c|c|c|c|c|c|c|c|}
\hline  & $\begin{array}{c}0,0 \\
a \\
1,0\end{array}$ & $\begin{array}{l}1,0 \\
a \\
2,0\end{array}$ & $\begin{array}{c}2,0 \\
a \\
3,0\end{array}$ & $\begin{array}{c}3,0 \\
a \\
4,0\end{array}$ & $\begin{array}{c}4,0 \\
a \\
5,0\end{array}$ & $\begin{array}{l}5,0 \\
a \\
6,0\end{array}$ & $\begin{array}{c}6,0 \\
a \\
7,0\end{array}$ & $\begin{array}{c}7,0 \\
a \\
8,0\end{array}$ & $\begin{array}{l}8,0 \\
a \\
9,0\end{array}$ \\
\hline $\begin{array}{l}\text { Areias Marinhas e areias } \\
\text { marinhas retrabalhadas }\end{array}$ & - & - & - & - & 15 & 69 & 8 & 8 & - \\
\hline $\begin{array}{l}\text { Fm Pariquera-Açu (cinza } \\
\text { a branco) }\end{array}$ & - & - & - & 14 & 72 & - & 14 & - & - \\
\hline $\begin{array}{l}\text { Fm Pariquera-Açu (cas- } \\
\text { tanha amarelada) }\end{array}$ & - & - & - & - & 21 & 22 & 57 & - & - \\
\hline
\end{tabular}


Rev. IG, São Paulo, 1(2):5-24, jul./dez. 1980

DISTRIBUIÇÃO AREIA

\begin{tabular}{|c|c|c|c|c|c|c|c|c|c|}
\hline Grupo & $\begin{array}{c}0,0 \\
a \\
1,0\end{array}$ & $\begin{array}{l}1,0 \\
a \\
2,0\end{array}$ & $\begin{array}{c}2,0 \\
a \\
3,0\end{array}$ & $\begin{array}{c}3,0 \\
a \\
4,0\end{array}$ & $\begin{array}{c}4,0 \\
\mathrm{a} \\
5,0\end{array}$ & $\begin{array}{l}5,0 \\
a \\
6,0\end{array}$ & $\begin{array}{c}6,0 \\
\text { a } \\
7,0\end{array}$ & $\begin{array}{c}7,0 \\
a \\
8,0\end{array}$ & $\begin{array}{l}8,0 \\
a \\
9,0\end{array}$ \\
\hline $\begin{array}{l}\text { Areias Marinhas e areias } \\
\text { marinhas retrabalhadas }\end{array}$ & - & - & - & 100 & - & - & - & - & - \\
\hline $\begin{array}{l}\text { Fm Pariquera-Açu (cinza } \\
\text { a branco) }\end{array}$ & 14 & 29 & 57 & - & - & - & - & - & - \\
\hline $\begin{array}{l}\text { Fm Pariquera-Açu (cas- } \\
\text { tanha amarelada) }\end{array}$ & - & 43 & 57 & - & - & - & - & - & - \\
\hline
\end{tabular}

TABELA 3 - Parâmetros Texturais - Grau de Seleção - \% de Amostras DISTRIBUIÇãO TOTAL

\begin{tabular}{|c|c|c|c|c|c|c|}
\hline$\underbrace{\sigma_{I}}_{\text {Grupo }}$ & 0,35 & $\begin{array}{c}0,35 \\
a \\
0,50\end{array}$ & $\begin{array}{c}0,50 \\
a \\
1,00\end{array}$ & $\begin{array}{c}1,00 \\
a \\
2,00\end{array}$ & $\begin{array}{l}2,00 \\
a \\
4,00\end{array}$ & 4,00 \\
\hline $\begin{array}{l}\text { Areias Marinhas e } \\
\text { areias marinhas re- } \\
\text { trabalhadas }\end{array}$ & - & - & - & 38 & 62 & - \\
\hline $\begin{array}{l}\text { Fm Pariquera-Açu } \\
\text { (cinza a branco) }\end{array}$ & - & - & - & - & 100 & - \\
\hline $\begin{array}{l}\text { Fm Pariquera-Açu } \\
\text { (castanha-amarela- } \\
\text { da) }\end{array}$ & - & - & - & - & 100 & - \\
\hline
\end{tabular}

DISTRIBUIÇÃO AREIA

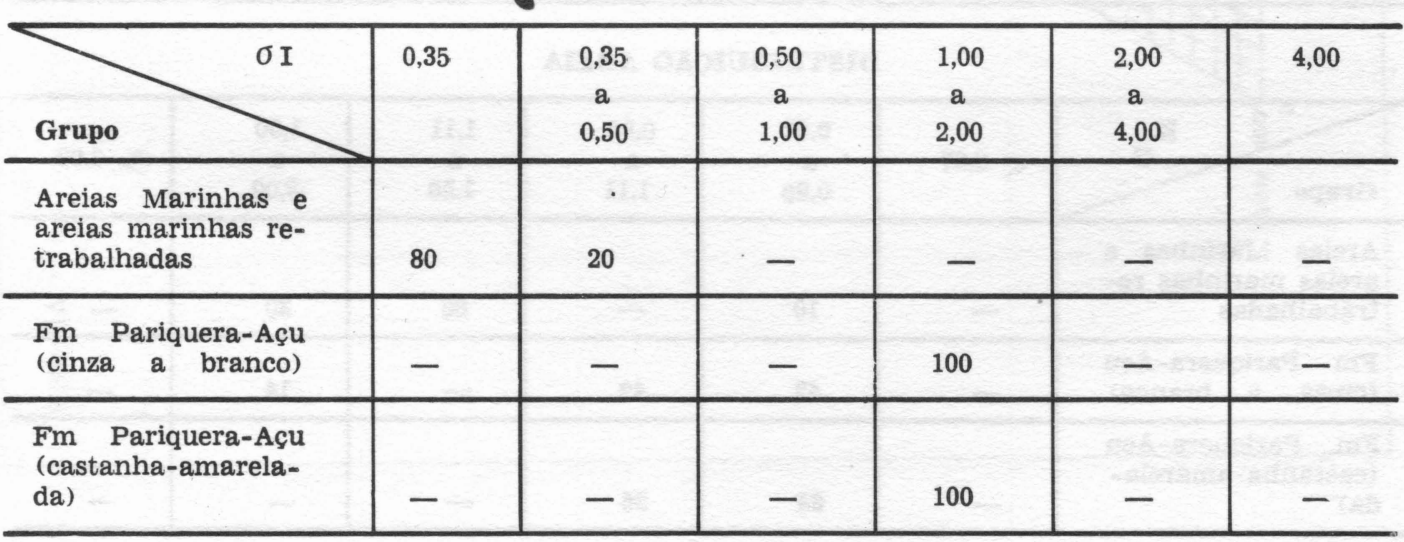


Rev. IG, São Paulo, 1(2):5-24, jul./dez. 1980

TABELA 4 - Parâmetros Texturais - Grau de Assimetria - \% de Amostras DISTRIBUIÇAO TOTAL

\begin{tabular}{|c|c|c|c|c|c|}
\hline$\underbrace{\text { SK }}_{\text {Grupo }}$ & $\begin{array}{l}-1,00 \\
a \\
-0,30\end{array}$ & $\begin{array}{l}-0,30 \\
a \\
-0,10\end{array}$ & $\begin{array}{c}-0,10 \\
a \\
+0,10\end{array}$ & $\begin{array}{c}+0,10 \\
a \\
+0,30\end{array}$ & $\begin{array}{c}+0,30 \\
a \\
+1,00\end{array}$ \\
\hline $\begin{array}{l}\text { Areias Marinhas e } \\
\text { areias marinhas re- } \\
\text { trabalhadas }\end{array}$ & 15 & - & - & - & 85 \\
\hline $\begin{array}{l}\text { Fm Pariquera-Açu } \\
\text { (cinza a branco) }\end{array}$ & 14 & - & - & 14 & 72 \\
\hline $\begin{array}{l}\text { Fm Pariquera-Açu } \\
\text { (castanha-amarela- } \\
\text { da) }\end{array}$ & 72 & 7 & 7 & 7 & 7 \\
\hline
\end{tabular}

DISTRIBUIÇAO AREIA

\begin{tabular}{|c|c|c|c|c|c|}
\hline $\begin{array}{l}\text { Areias Marinhas e } \\
\text { areias marinhas re- } \\
\text { trabalhadas }\end{array}$ & 30 & 50 & 10 & 10 & - \\
\hline $\begin{array}{l}\text { Fm Pariquera-Açu } \\
\text { (castanha-amarela- } \\
\text { da) }\end{array}$ & 29 & 43 & 28 & - & - \\
\hline
\end{tabular}

TABELA 5 - Parâmetros Texturais - Curtose - \% de Amostras)

DISTRIBUIÇAOO TOTAL

\begin{tabular}{|c|c|c|c|c|c|c|}
\hline Grupo & $<0,67$ & $\begin{array}{c}0,67 \\
a \\
0,90\end{array}$ & $\begin{array}{c}0,90 \\
a \\
1,11\end{array}$ & $\begin{array}{c}1,11 \\
a \\
1,50\end{array}$ & $\begin{array}{c}1,50 \\
a \\
3,00\end{array}$ & $>3,00$ \\
\hline $\begin{array}{l}\text { Areias Marinhas e } \\
\text { areias marinhas re- } \\
\text { trabalhadas }\end{array}$ & 77 &  & - & - & 8 & - \\
\hline $\begin{array}{l}\text { Fm Pariquera-Açu } \\
\text { (castanha-amarela- } \\
\text { da) }\end{array}$ & 93 & 7 & - & - & - & - \\
\hline
\end{tabular}

DISTRIBUIÇÃO AREIA

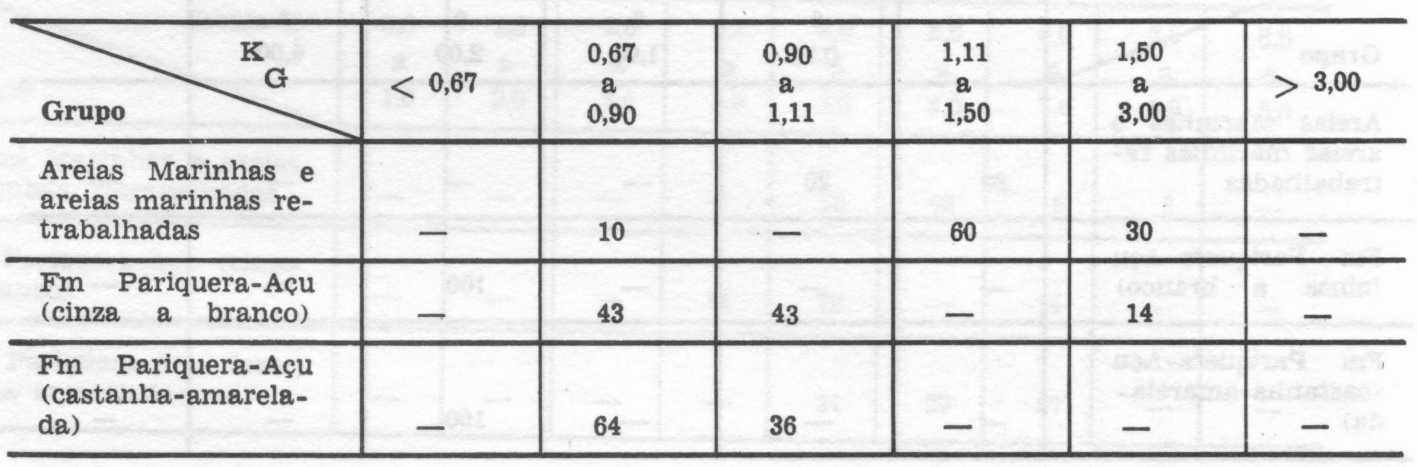


Rev. IG, São Paulo, 1(2):5-24, jul./dez. 1980

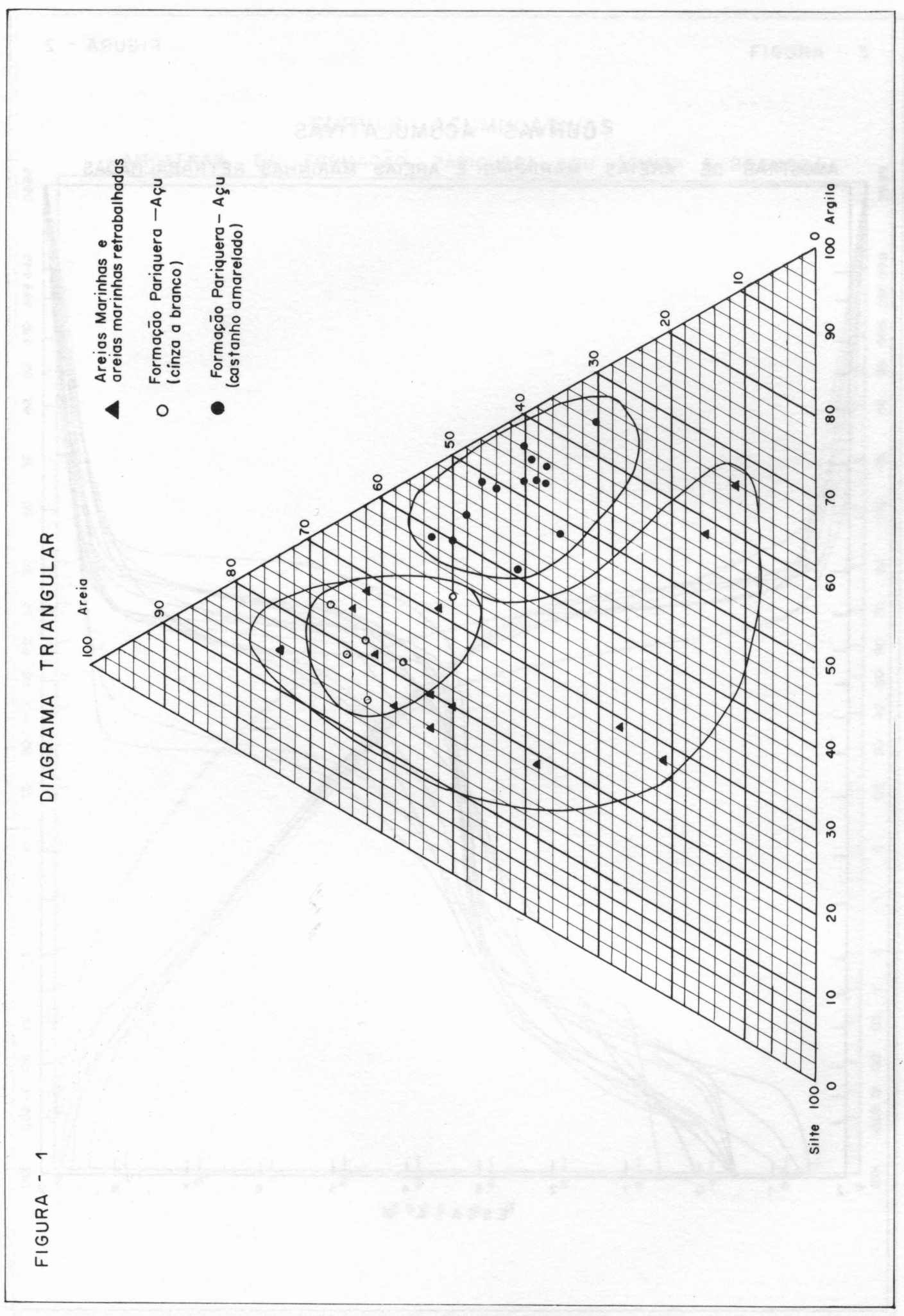


CURVAS ACUMULATIVAS

AMOSTRAS DE AREIAS MARINHAS E AREIAS MARINHAS RETRABALHADAS




Rev. IG, São Paulo, 1(2):5-24, jul./dez. 1980
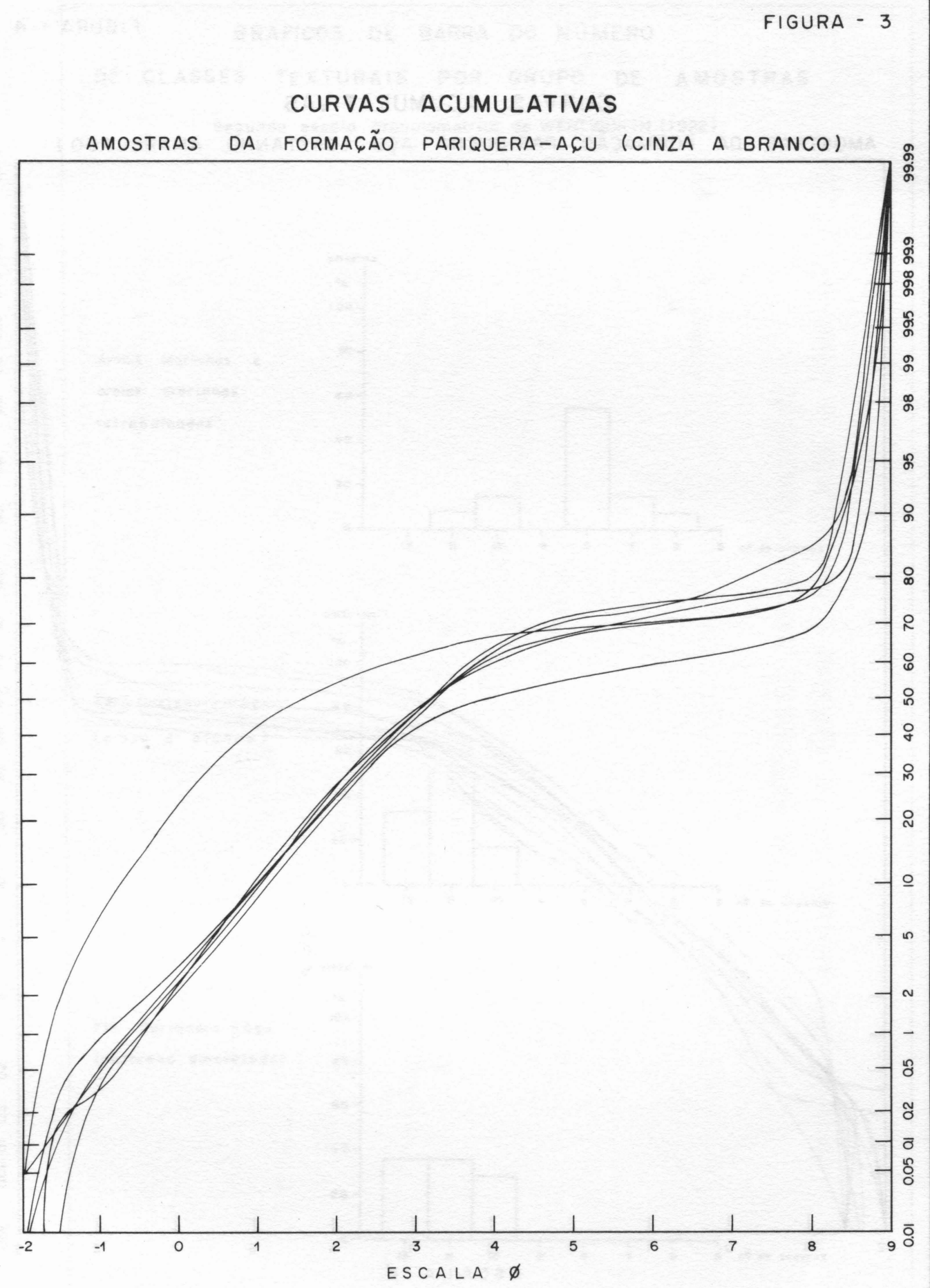
Rev. IG. São Paulo, 1(2):5-24, jul./ dez. 1980

FIGURA - 4

\section{CURVAS ACUMULATIVAS}

\section{AMOSTRAS DA FORMACÃO PARIQUERA-ACU (CASTANHO AMARELADO)}




Rev. IG, São Paulo, 1(2):5-24, jul./dez. 1980

\section{GRÁFICOS DE BARRA DO NÚMERO}

DE CLASSES TEXTURAIS POR GRUPO DE AMOSTRAS

Segundo escala granulométrica de WENTWORTH (1922)

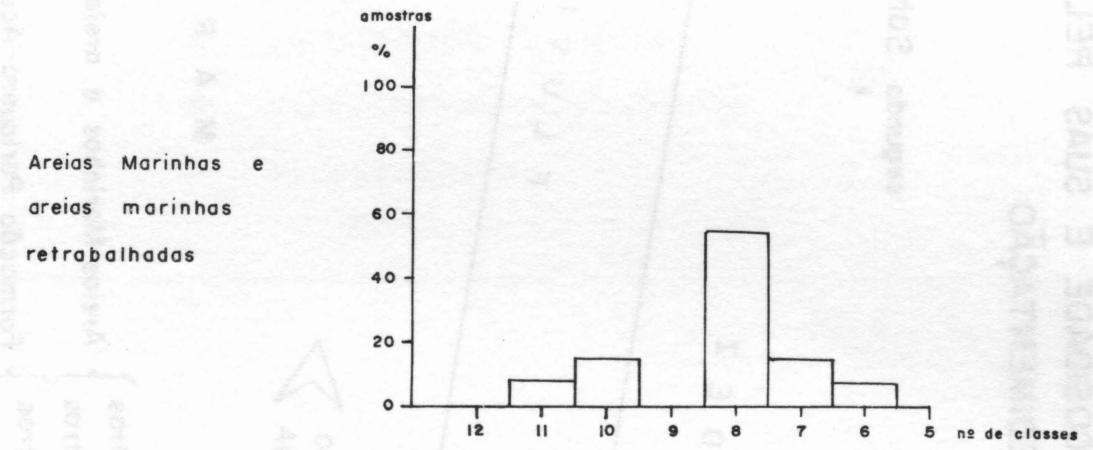

Fm. Pariquera-Agu

(cinza a branco)

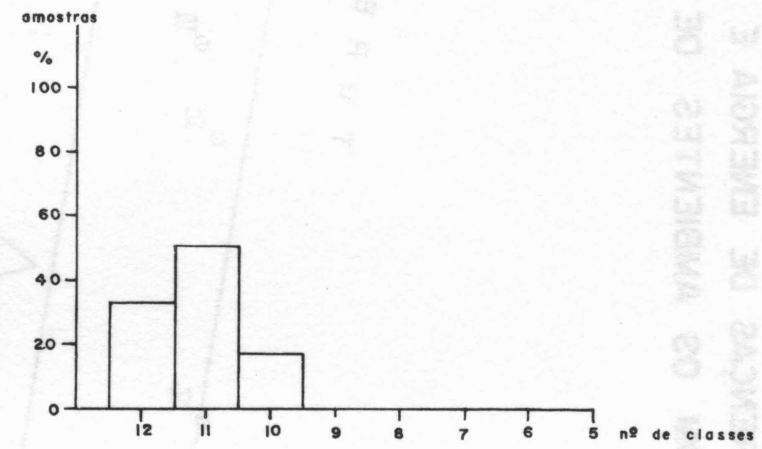

Fm. Pariquera - Acu

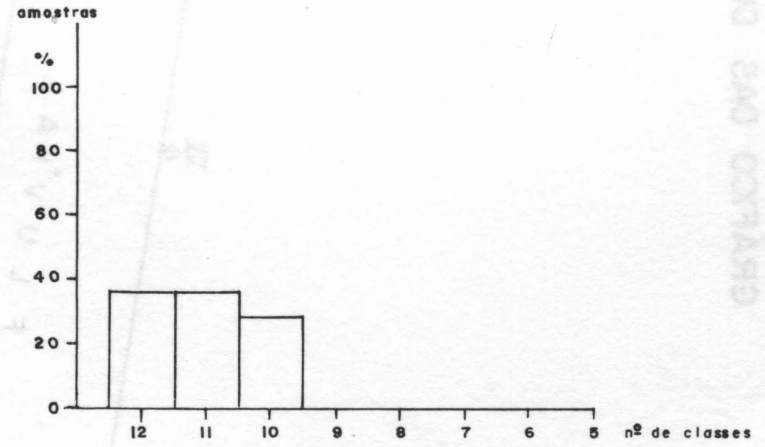

FIGURA - 5 
Rev. IG, São Paulo, 1(2):5-24, jul./dez. 1980

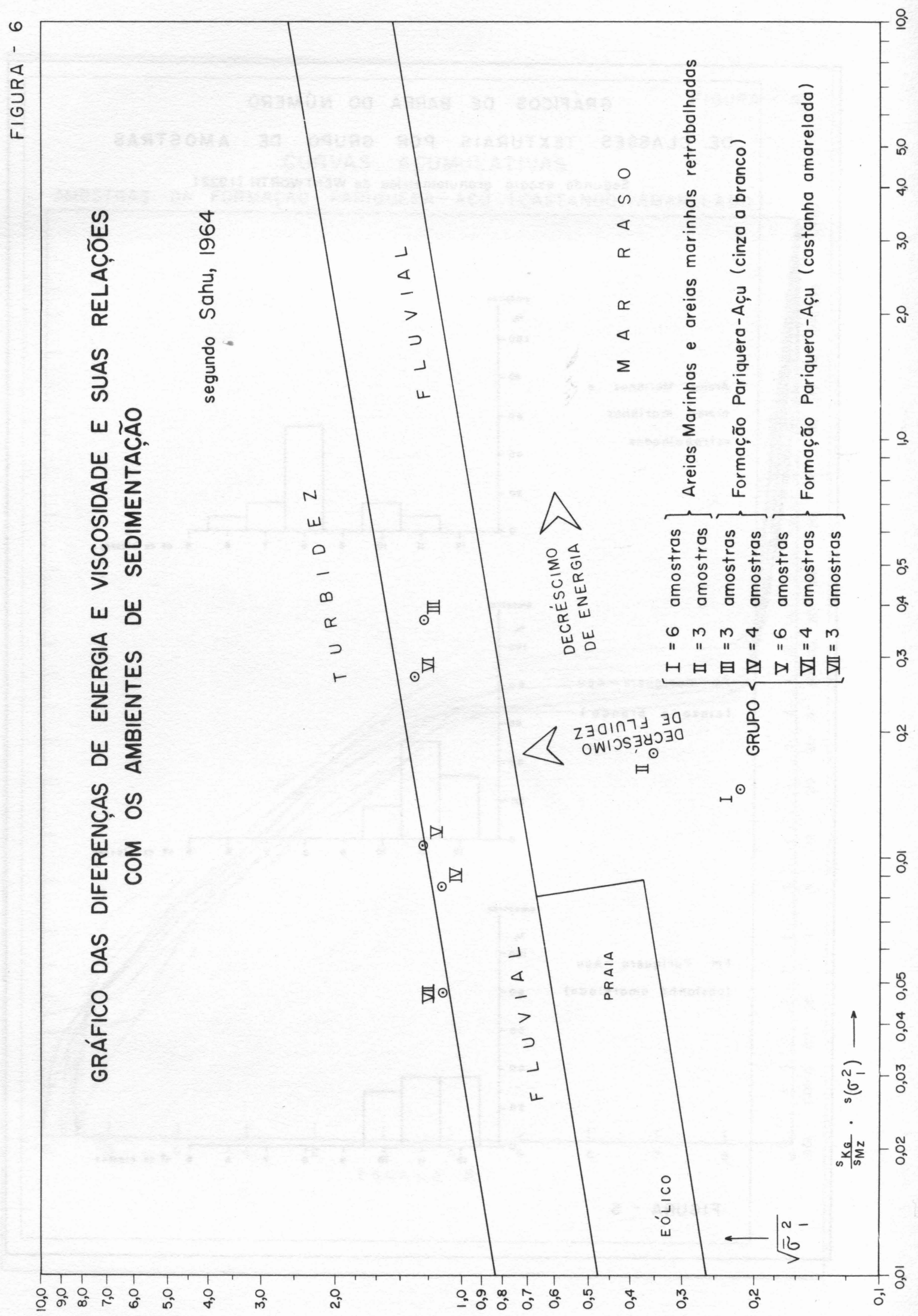


MAPA AFLORAMENTO

ÁREA LIMITROFE a NNW DA PLANÍCIE COSTEIRA dE CANANÉIA-IGUAPE






\section{MAPA GEOLO'GICO}

AREA LIMITTROFE A NNW DA PLANÍCIE COSTEIRA DE CANANÉIA-IGUAPE

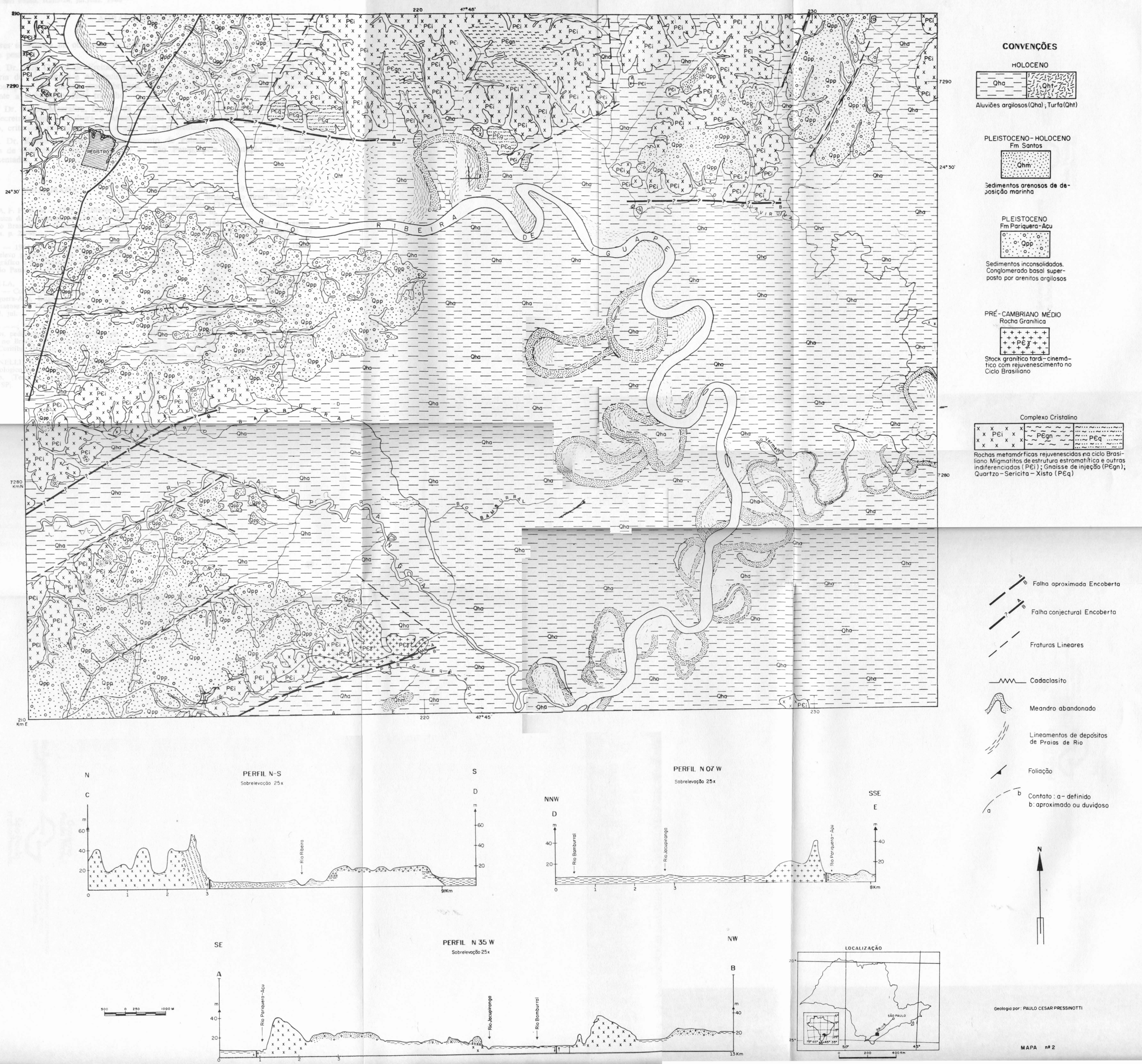




\section{AGRADECIMENTOS}

Os autores se sentem na obrigação de expressarem os mais sinceros agradecimentos às seguintes pessoas:

- Prof. Dr. Ruy Ozório de Freitas, Assessor Técnico do Instituto Geológico, da Secretaria de Agricultura e Abastecimento do Estado de São Paulo, pelas descrições microscópicas de rochas precambrianas, pela orientação e sugestões apresentadas durante a elaboração deste trabalho.

- Prof. Dr. Sergio Mezzalira, Diretor da Divisão de Geologia do Instituto Geológico, da Secretaria de Agricultura e Abastecimento do Estado de São Paulo, pela orientação, criteriosa revisão do texto e sugestões apresentadas.

- Prof. Dr. Kenitiro Suguio, do Departamento de Paleontologia e Estratigrafia, Instituto de Geociências da Universidade de São Paulo, pela orientação e sugestões apresentadas.

\section{BIELIOGRAFIA}

ALMEIDA, F. F. M. de - 1969 - Diferenciação tectônica da plataforma brasileira. In: Congresso Brasileiro de Geologia; 23.․, Brasília. Anais. p. 29-46.

- 1964 - Fundamentos geológicos do relevo paulista. In: São Paulo. Instituto Geográfico e Geológico. Geologia do Estado de São Paulo. p. 167-263. (Bol. 41)

BIGARELlA, J. J.; MOUSINHO, M. R. 1965 - Contribuição ao estudo da formação Pariquera-Açu, Estado de São Paulo. Bol. Paranaense de Geografia, Curitiba, (16/17): 17-42, jul.

-; - _ ; SILVA, J. X. - 1965 - Pediplanos, pedimentos e seus depósitos correlativos no Brasil. Bol. Paranaense de Geografia, Curitiba, (16/17): 117-152, jul.

FRANZINELLI, E. - 1970 - Estudo sedimentológico da formação Pariquera-Açu, São Paulo. Tese de Mestrado apresentada ao IG-USP|.
FREITAS, R. O. de - 1951 - Ensaio sobre a tectônica moderna do Brasil. São Paulo, Universidade. FFCL. 120p. (Boletim, 130 - Geologia, 6).

RICH, J. L. - 1953 - Problems in Brazilian geology and geomorphology suggested by reconnaissance in summer of 1951. São Paulo, Universidade. FFCL. 80p. il. (Boletim, 146 - Geologia, 9).

SILVA, A. T. S. F. da; CHIODI FILHO, C.; CHIODI, D. K.; PINHO FILHO, W. D. de - 1977. Projeto Santos Iguape; relatório final, geologia, v. I. São Paulo, DNPM/ CPRM, 640p. il.

SILVEIRA, J. D. - 1952 - Baixadas litorâneas quentes e úmidas. São Paulo, Universidade. FFCL. (Boletim, 152 - Geografia, 8).

SIMPOSIO INTERNACIONAL DA EVOLUÇÃO DA COSTA NO QUATERNÁRIO, São Paulo. 1978. Formações quaternárias marinhas do litoral paulista e sul fluminense por| Kenitiro Suguio $\mid$ e| Louis Martin. São Paulo, Instituto de Geociências, Sociedade Brasileira de Geologia. (Special Publication, I). 